\title{
Changing Perceptions of Macrodistributive Justice in China: A Comparative Analysis Based on CGSS2005 and CGSS2015
}

Rong $\mathrm{Hu}$

Guangzhou University

Ziyao Zeng

Guangzhou University

Zekai Lu (D1903500028@e.gzhu.edu.cn)

Guangzhou University https://orcid.org/0000-0001-8015-3071

Ying Xie

Guangzhou University

\section{Research Article}

Keywords: Macrodistributive Justice, Social Stratification, Changing Perception

Posted Date: November 15th, 2021

DOl: https://doi.org/10.21203/rs.3.rs-990615/v1

License: (a) (i) This work is licensed under a Creative Commons Attribution 4.0 International License. Read Full License 


\section{Abstract}

We use comparative data from CGSS2005 and CGSS2015 to explore people's changing perceptions of macrodistributive justice in China. Despite the widening income gap, the public's recognition of distribution justice has increased. Significant economic growth has improved people's tolerance for income differentiation and helps to explain the stability of the social structure in China. However, potential benefit differentiation, status changes, intergenerational differences, values and other factors have greatly increased the disequilibrium of justice perceptions.

\section{Introduction}

Since the reform and opening up, China has achieved remarkable success in terms of the economy. Meanwhile, coinciding with the rapid growth of housing prices and the diffusion of the internet, a widening trend of social inequality and income differentiation has appeared. Some scholars assert that the public will accept the current inequality rather than complain (Whyte 2009), and Chinese society has certain mechanisms for mitigating the social harms caused by inequality (Xie 2010). Nevertheless, there are also scholars who believe that the disequilibrium of interest relationships is a burning issue and that allowing it to increase will lead to high disequilibrium in terms of social mentality (L. Sun 2011). Regarding this situation, there have been an increasing number of discussions in recent years on the subjective perception and cognitive evaluation of social differentiation inequality (Wu 2009). Whether the income gap is serious depends on the public's value judgement (Wegener 2000). The public's perception of distributive justice determines the acceptance of economic and political legitimacy, and the public's interpretation of distributive justice relates to the design of the country's basic economic, political and social systems (Burstein 2003; Lipset and Ladd Jr 1972). Therefore, to interpret the development of Chinese society, it is of great practical significance to carry out analysis and discussion of the perception of distributive justice.

\section{Literature Review And Research Hypothesis}

The perception of distributive justice refers to people's awareness of equity in the distribution of important social resources and can be divided into the perception of microjustice and the perception of macrojustice according to differences at the analytical level (Wegener 2000). The former indicates one's personal judgement of whether he or she obtains justice for his or her own resources, while the latter regards society as a whole and represents the justice values of social systems such as the income distribution system, tax system, and political participation system.

By comparison, as the evaluation objectives of the perception of macrodistributive justice have certain consistency, it is more likely to evolve into a social consensus or social mentality, which will instrumentally influence the overall social structure. Therefore, macrodistributive justice is of greater research significance. China's transition from a planned economy to a market economy has broken both the egalitarian commitment of socialist ideology and the egalitarian distribution model under the 
redistribution system, and while it has created a miracle of rapid and sustainable economic growth, social problems such as inequality of opportunity, disparity between rich and poor, and urban-rural disparity are becoming increasingly serious. In the abovementioned context, do the public show more unease or dissatisfaction with the level of social inequality? Does the trend of social struggles and mass incidents in recent years mean that the public think Chinese society is becoming more unequal and unfair? How did the factors that influence the perception of social justice change? In this regard, we focus on the overall perception of the macrodistributive justice cognitive difference model, reviewing the existing studies theoretically from three perspectives-social structure, values and institutional changes-and we advance the hypotheses of this study based on these three perspectives.

\subsection{Social Structure}

Social structure has always been considered an important factor affecting the perception of distributive justice. 'Structural determinism' based on self-interest theory holds that with higher economic status, a person becomes more likely to maintain the existing distribution pattern and recognize its justice (Kluegel and Smith 2017). However, 'local comparison', based on relative deprivation theory, gives more attention to people's subjective perceptions caused by their change in status and holds that, through 'relative deprivation' in a 'social comparison', frequent class flow and status changes have a profound influence on people's perceptions of distributive justice (Adams 1965; Geschwender 1967).

Empirical research in China has shown that there is no linear correspondence between objective social status and the perception of distributive justice. First, many Chinese people agree that inequality is an inevitable consequence of economic growth and agree that traditional Chinese political ideology has promoted merit-based inequality (Xie 2010); second, reform and opening up have brought many new opportunities to lower-class groups, such as farmers, and people of lower social status, especially vulnerable groups, are not necessarily dissatisfied with the current inequality (Whyte 2009). This article agrees that in the early stage of the market economy transition, all social strata generally benefit from the situation, so the public tends to positively evaluate the social distribution. However, with the widening of the distribution gap and the gradual solidification of social classes, the influence of structural factors, such as economic status, on the differentiation of the perception of justice will become more noticeable. The higher the economic status of a person, and the more obvious the advantages of income and wealth, the more inclined the person is to recognize the established distribution pattern, while in contrast to the strong rise of the overall economy and the rapid rise of the nouveau riche, the experience of relative deprivation of status and relative damage to benefits will strengthen people's perceptions of social macro-inequality.

The unit system is an important structural feature with characteristics specific to China. Under the existing mixed economic system, differences in units represent different forms of property rights and distribution systems and the degree of market transition. Studies have found that members of the CPC (the Communist Party of China) and people who work in government offices, public enterprises and institutions with a lower degree of marketization are more receptive to the 'equality principle', while private 
sector employees with a higher degree of marketization and farmers favour 'the principle of desert' (M. Sun 2009); there are also studies showing that people who are working or have worked in state-owned enterprises are apt to think that the income gap is too large (Whyte 2009). However, with the deepening and advancement of the market transformation, the function of the redistribution system is continually weakened and the function of the market system is continually strengthened; state-owned enterprises have gradually established a market-oriented wage determination mechanism, and public institutions have gradually established and implemented a performance-based wage determination system. These factors will weaken the egalitarian mechanism in the redistribution system to some extent. Thus, the number of workers in the redistribution system who accept the 'deserving principle' will increase with the advancement of the market transition, and this will therefore encourage tolerance for an income gap.

Accordingly, the following hypotheses are formulated:

Hypothesis a1: Increased income strengthens the perception of macrodistributive justice.

Hypothesis a2: Increased family wealth strengthens the perception of macrodistributive justice.

Hypothesis a3: Increased status flow strengthens the perception of macrodistributive justice.

Hypothesis a4: The cognitive differences in the perception of macrodistributive justice between party and nonparty members and workers inside and outside the public economic system will contract.

\subsection{Values}

Unlike 'structural determinism', cultural theory usually emphasizes that people's attitudes towards stratification are influenced by mainstream social values and other specific beliefs (Abercrombie and Turner 1978). At the empirical level, Deutsch summarized three main distribution principles: the principle of equality, the principle of desert based on individual input and contribution (Desert, or Equity as Desert), and the principle of distribution according to individual needs (Need) (Deutsch 1975). At the individual level, four values of justice have been distinguished by scholars: the advocates of ascription theory regard the established distribution of resources as natural and self-evident; egalitarians contend that the distribution should ensure maximum social justice; individualists believe that a free and fair competition system does exist; and fatalists blame social inequality for their misfortunes. Among groups with various values, there are significant differences in the subjective recognition of a fair income gap (Verwiebe and Wegener 2000). Social transformation is not only the transformation of the economic level and social structural level but also the transformation of people's values. In summary, at least the three perspectives below can be used to discuss changes in values and their influence on the perception of justice. 
First, cohort (generation or age) differences are an important reason for a divergence of values. Differences in the socialization environment for certain cohorts can lead to cognitive differences in their perception of justice. In the 1960s and 1970s, empirical studies of Western societies found that young people were more likely than older people to pursue justice because of egalitarian ideas, while post-socialist countries that have experienced market transformations have found diametrically opposed cohort effects. In post-transition Estonia, the older cohort is more critical of income inequality than the younger cohort (Saar 2008). For a long time, Chinese people were deeply influenced by the traditional idea that 'inequality should be of more concern than insufficiency', and before reform and opening up, Chinese people lived in a more equal and less hierarchical society (Whyte 2009); because of the distribution system of the planned economy, the 'average principle' was accepted by the public, emphasizing that resources should be allocated on average or on demand to members of society. The economic reform in the late 1970s introduced market mechanisms, emphasizing breaking the "iron bowl" (lifelong job) and widening the income gap. From then on, 'the principle of desert' began to be accepted and people gradually began to adapt to distributional disparity and inequality, which is more evident in the post-transition (i.e., after the 1980s) cohorts. Since young cohorts did not experience the era of the egalitarian planned economy, as they grew up in the years of rapid economic development and the gradual promotion of market rules, they are more receptive to "the principle of desert" that one's rewards should be consistent with one's contribution, input and cost. They recognize that "the greater the contribution, the higher the remuneration", and they have greater tolerance for the inequality of the macro income distribution.

Second, education has an enlightening effect on attitudes towards inequality. Regarding how education affects people's attitudes, there are different understandings in academia. Education has long been regarded as an important part of human capital, and the influence of income and education has been used to confirm self-interest theory. Consistent with the expectations of self-interest theory, the higher the level of education, the more inclined people tend to be toward the principle of desert (M. Sun 2009), and the more educated people are, the more they tend to have a positive attitude towards social inequality (Zhang 2004). However, in recent years, scholars have begun to re-examine and test this opinion, and another diametrically opposed theoretical hypothesis, the principle of enlightenment, has attracted the attention of the academic community. This theory holds that the enlightening nature of education conveys a value of compassion for poor and vulnerable groups, and therefore, there is a positive correlation between educational level and the tendency to support equality (Robinson and Bell 1978).

Under the specific background of Chinese society, the influence of education on attitudes toward social inequality should be more consistent with the theoretical expectation of the principle of enlightenment. In enlightenment theory, 'cognitive development theory' and 'socialization theory' provide two theoretical paths to explaining the correlation between education and liberal attitudes (Phelan et al. 1995). According to cognitive development theory, education can improve people's knowledge accumulation and cognitive ability, making people more likely to understand the real situation of growing social inequality in the transition period; additionally, more educational experience will lead people to develop critical thinking 
and analytical habits. From socialization theory, the core values conveyed by China's education system are collectivism and socialism, which may also make more educated people more sympathetic to the plight of the poor and more concerned about the overall situation of social development. Therefore, more educated people will pay more attention to social polarization, and in turn, they will become more critical of inequality (J. Li and Wu 2012).

Third, internet media communication has strengthened people's perception and evaluation of social inequality. The 'cultivation theory' holds that people who have more exposure to mass media are more likely to accept the social world depicted by the media. First, regarding internet media, unlike traditional media such as newspapers, radio and television, its self-organization is relatively strong, and thus everyone can use the internet to participate in the discovery, collection, processing and dissemination of information, making traditional media's "gatekeeper" power collapse and transfer (Lu and Quan 2015), possibly leading to an increase in the amount of negative information disseminated by internet media. In fact, on the internet, although bold 'wealth flaunting' can usually be seen, poverty and suffering avoided by traditional media can also be exposed. Therefore, internet media show great differences between the resource distribution and lifestyle of different groups, which strengthens people's perception and evaluation of the current situation of social inequality. In addition, based on people's perception, internet media provides people with a broader social comparison basis and reference group range. According to the relevant research, in the information age and through the influence of the internet and mass media, the information acting on intergroup comparison has increased greatly, the public has become more familiar with the income and consumption patterns of the upper classes in society and the impact of the relative deprivation of groups on people's perception of justice has been increasing (Hamilton 2002; Schor 1998, 1999).

In summary, based on the influence of cohort, education and internet media on values and subjective perceptions, the following hypotheses are advanced:

Hypothesis b1: Young cohorts have a higher perception of social inequality.

Hypothesis b2: With the advancement of marketization transformation, education has become more critical of social inequality.

Hypothesis b3: The greater the usage of the internet, the more critical one is of social inequality.

Hypothesis b4: With the development of information technology, the influence of the internet on the perception of justice has increased.

\subsection{Institutional Changes}

Based on the study of social attitude change in developed societies, scholars summarize the trends of social attitude change in three basic forms (L. Li and Wang 2018; Schreiber 1978). 
The massification/consistency hypothesis holds that modernization leads to increased homogeneity and decreased heterogeneity among people, so the differences in attitudes and behaviours between various groups in society will gradually narrow with the development of modernization (Glenn and Simmons 1967). In contrast, the disequilibrium/structure hypothesis contends that changes in social attitudes occur first in specific groups of people and then in others. In this process, the change in social attitudes will gradually permeate from some groups to other groups with a certain social structure, so the rate of attitude change will be different due to structural factors (Schreiber 1978). The polarization hypothesis holds that social attitudes are becoming fragmented or even polarized, especially in the area of political issues (DiMaggio et al. 1996).

In our opinion, although the gap between the rich and poor has widened in the past decade, the general public's assessment of macrosocial justice will not deteriorate significantly for this reason. In fact, the advancement of marketization transformation will probably increase people's tolerance of social inequality to some extent. There are at least three reasons: first, despite the significant increase in income inequality, economic growth is always maintained at a high rate, and people's living standards have generally improved effectively. According to the National Bureau of Statistics of China, real growth in disposable income per capita remained above 10\% in 2005-2015 ("The growth of per capita disposable income of rural residents from 1978 to 2019 ", n.d.), and this was the most significant increase in income since 1978. At the same time, livelihood projects are gradually becoming the primary task of the government, and the result of economic development leads to the improvement of people's livelihood level; the livelihood development index of nearly half of the regions in China ranked above the per capita GDP ranking, and the public has enjoyed an economic development dividend. A study shows that China has had broader beneficiaries from its economic growth than the United States and European countries (Piketty et al. 2019, pp. 1978-2015).

Second, the effective promotion of poverty alleviation and the gradual improvement of the social security system have set up a safety net for the lowest economic groups, which has compensated for the relative interest loss in the reform to some extent. Although the concept of distribution justice of the average principle exists widely at the bottom of society, which may easily lead to the recognition of inequality regarding the distribution gap (Ming 2009), since the turn of the century, the government has vigorously promoted poverty alleviation and accelerated the construction of a social security system. This has brought remarkable results, enhancing the sense of gain of the bottom and vulnerable groups and playing a positive role in bridging the social divide caused by the disparity between rich and poor.

Third, as the principle of desert is gradually becoming accepted by the public with market-oriented promotion and the legitimacy of the market-oriented resource distribution system has been confirmed by more than 40 years of successful experience in reform and opening up, the rapid accumulation of market wealth and the competitive market atmosphere have made people more aware of the established rules of resource distribution and have led to an acknowledgement that greater ability deserves higher returns. Based on the above judgement, despite the widening income gap, the public remains relatively optimistic, and the acceptance and tolerance of distributive differences are moving in a positive direction. 
Based on institutional changes, the following hypotheses are formulated:

Hypothesis c1: With the advancement of marketization, the public's acceptance of macrodistributive differences is increasing.

Hypothesis c2: The higher the degree of marketization a region is in, the higher the perception of distributive justice it has.

\section{Compliance With Ethical Standards}

This study used the publicly available data only. No experiments were conducted, nor were patients or animals involved in this study. Therefore, this study does not require ethical approval. The authors declare that there are no conflict of interest regarding the publication of this paper.

\section{Data Variables And Analytical Models}

This paper uses the China General Social Survey (CGSS) 2005 and 2015 data to compare the change process of the perception of macrodistributive justice. Since 2003, the CGSS has regularly and systematically collected data on all aspects of Chinese society, covering 31 provinces across the country and conducting sampling surveys in accordance with strict criteria. CGSS 2005 has 10372 urban and rural samples, and CGSS2015 has 10968 urban and rural samples. These two sets of data pose the same questions for both the perception of macrodistributive justice and the relevant explanatory variables, which makes this a good comparison and analysis sample.

The dependent variable of this study is the perception of macrodistributive justice, that is, the subjective value judgement of whether the overall distribution result and distribution mechanism are fair. The 2005 and 2015 questionnaires pose questions in which respondents rate their attitudes towards the statement that 'some people now earn more and some earn less, but that is fair', and the answers were divided into six levels: 'strongly agree,', 'agree', 'neutral', 'disagree', 'strongly disagree' and 'cannot choose'. In this study, we excluded samples that selected 'cannot choose' and assigned values to the answers. We set the answer as an ordinal variable: according to the answers from 'strongly agree' to 'strongly disagree', numbers from 1 to 5 were assigned to the variable; the higher the dependent variable's value, the more likely a person is to think that the macrodistribution disparity is not fair.

There are three types of explanatory variables in this study: explanatory variables of structure, explanatory variables of values and explanatory variables of institutional changes. Explanatory variables of structure include the following: (1) Individual class status: According to the individual's subjective evaluation of his or her own social status, there are five grades, 'lower', 'lower-middle', 'middle', 'uppermiddle', and 'upper'; for the change in social status in recent years, there three grades, going up, going down and almost the same. (2) Personal income: The questionnaire asked the respondents' income in the 
previous year. This is an interval variable. (3) Family wealth: Considering the sharp rise in asset prices such as housing prices over the past decade, real estate has become the most important part of China's family wealth structure. This study uses the spare houses (or apartments) that a family owns but does not live in as a measure of family wealth. A respondent whose family has more than 1 house is assigned 1 ; otherwise, the respondent is assigned 0 . (4) Political identity: A party member is assigned 1 ; a nonparty member is assigned 0. (5) Unit type: Workers inside the public economic system (including state-owned enterprises, public institutions, party and government offices, etc.) are assigned 0; employees outside the public economic system (foreign investment, private enterprises, self-employed, etc.) are assigned 1 .

Explanatory variables of values include the following: (1) Education: There are six grades, 'primary school and below', 'junior high school', 'high school/vocational school', 'junior college', 'bachelor's degree', and 'master's degree and above'. (2) Cohort: According to the year of birth of the respondents, there are six grades, 'post-40s', 'post-50s', 'post-60s', 'post-70s', 'post-80s', and 'post-90s'. (3) Usage of internet media: According to the frequency of the respondents' browsing of the internet, there are five grades, 'never', 'rarely', 'sometimes', 'regularly', and 'frequently'. In addition to the three variables, the study included commonly used control variables such as gender (male $=1)$ and household registration $(c i t y=1)$.

The NERI Index of Marketization of China's Provinces was chosen as the explanatory variable of institutional changes to evaluate the differences in the process of marketization between various provinces. This useful index was proposed by Fan et al. (2001). The value of this index does not indicate the absolute degree of marketization but rather the relative position of a province in the process of marketization compared with the provinces with the highest and lowest degrees of marketization at the time. In this study, according to the value of the NERI Index of Marketization, the degree of marketization in a province is divided into three grades: high, middle and low.

The dependent variable, perception of macrodistributive justice, is a subjective evaluation of an ordinal variable; the study uses an ordered logit model for analysis (McCarter 2009; Menard 2002), the formula of which is as follows:

$$
\log \left(\frac{P_{\left(y_{i \leq j}\right)}}{1-P_{\left(y_{i \leq j}\right)}}\right)=\tau_{j}-a-b x_{i}
$$

To analyse the changes in the perception of macrodistributive justice and its influence mechanism over the course of a decade, by comparing the data analysis models for 2005 and 2015, we analysed the regression of the samples for the two years individually and used a permutation test to examine the differences in the two years' regression coefficients (the test's basic idea is to resample the existing samples to obtain empirical samples and construct the empirical distribution of the statistics $d$ and the 
differences in the coefficient to obtain the empirical p-value of the distribution) (Efron and Tibshirani 1994).

\section{Results Of The Analysis}

Based on CGSS data, we analysed the inequality of the income distribution between individuals in 2005 and 2015 according to the total income of the individuals (including occupational and property income) in the previous year, as shown in Table 1. Between 2005 and 2015, overall income levels rose, with the mean and median of personal income rising 3.73 times and 3.45 times, respectively. Other than the bottom quintile income group, the average income of all subgroups increased significantly. At the same time, however, the distribution gap widened significantly: the share of total income of the top quintile income group increased from $56.45 \%$ to $64.74 \%$, the share of the bottom quintile dropped from $3.36 \%$ to $1.08 \%$, and the share of the third quintile also shrunk measurably. Accordingly, income differentiation intensified.

Table 1: Income inequality of personal annual income

\begin{tabular}{l|l|l|l|l}
\hline \multirow{2}{*}{} & \multicolumn{2}{|l|}{2005} & \multicolumn{2}{l}{2015} \\
\cline { 2 - 5 } & The share of the total & Mean (yuan) & The share of the total & Mean (yuan) \\
\hline Bottom quintile & $3.36 \%$ & 1290.49 & $1.08 \%$ & 845.90 \\
Second quintile & $5.60 \%$ & 3255.23 & $4.29 \%$ & 6203.50 \\
Third quintile & $12.24 \%$ & 5779.26 & $10.66 \%$ & 18536.35 \\
Fourth quintile & $22.35 \%$ & 9854.11 & $20.20 \%$ & 32955.13 \\
Top quintile & $56.45 \%$ & 25432.91 & $64.74 \%$ & 115842.15 \\
\hline Mean & 8792.43 & 32805.33 & \\
\hline Median & 5800 & 20000 & \\
\hline Std. Deviation & 12863.11 & 205840.6 & \\
\hline
\end{tabular}

Note: The data sources are CGSS2005 and CGSS2015

Consistent with our theoretical hypotheses, although income distribution is becoming increasingly unequal, the public does not seem to feel it is increasingly unfair as a result. As shown in Figure 1, from 2005 to 2015, there was a slight increase in the public's acceptance of macrodistributive inequality. Specifically, there were noticeable changes in the distribution of evaluation grades: while 'strongly agree' fell by $4.1 \%$, 'agree' rose by $10.4 \%$ and 'disagree' dropped by $4 \%$. Thus, although the perception of justice is essentially the subjective perception and evaluation of the fairness of the social resource distribution, which is affected by objective resource distribution mechanisms and results, the correspondence between the process and results of the distribution and the public's perception of justice is not simple. This supports the findings of existing studies that the objective socioeconomic status of the population does not necessarily represent their subjective attitude towards social inequality, and the Gini coefficient or 
another measure of income distribution may not provide an accurate prediction of the public's perception of these issues (Whyte 2009). In fact, the cognitive and evaluation mechanisms of the perception of justice are influenced by more complex social factors.

To examine the factors that affect the perception of distributive justice, the data for 2005 and 2015 are separately analysed in logit models from three perspectives: social structure, values and institutional changes. The results of the analysis are shown in Table 2: model 1 is the result of the analysis of the perception of distributive justice in 2005, and model 2 is the result of the same analysis for 2015 . In the table, the regression coefficient, odds ratio and cumulative probability ratio are reported.

The significance of the difference between the coefficients of the two regression equations is reflected by the empirical $p$-value of the permutation test.

Table 2: The results of regression analysis 


\begin{tabular}{|c|c|c|c|c|c|}
\hline & $\begin{array}{l}\text { Umodel 10 } \\
2005\end{array}$ & $\begin{array}{l}\text { Odds } \\
\text { ratio }\end{array}$ & $\begin{array}{l}\text { Umodel 2ロ } \\
2015\end{array}$ & $\begin{array}{l}\text { Odds } \\
\text { ratio }\end{array}$ & $\begin{array}{c}\text { Difference of } \\
\text { coefficient } \\
\text { [p-value } \square\end{array}$ \\
\hline Rural areas & $-0.235^{* * *}(0.047)$ & 0.791 & $-0.217^{* * *}(0.046)$ & 0.805 & $0.09^{*}$ \\
\hline Gender & $-0.030(0.039)$ & 0.971 & $0.032(0.040)$ & 1.033 & 0.39 \\
\hline
\end{tabular}

\section{Education (referent!primary school and}

below)

\begin{tabular}{|c|c|c|c|c|c|}
\hline Junior high school & $0.062(0.051)$ & 1.064 & $0.046(0.053)$ & 1.047 & 0.40 \\
\hline High school/vocational school & $0.159^{* * *}(0.061)$ & 1.172 & $0.156^{* *}(0.066)$ & 1.169 & 0.40 \\
\hline Junior college & $0.047(0.094)$ & 1.048 & $0.302^{* * *}(0.094)$ & 1.353 & 0.11 \\
\hline Bachelor's & $-0.085(0.123)$ & 0.918 & $0.204^{* *}(0.098)$ & 1.226 & $0.00^{* * *}$ \\
\hline Master's and above & $0.261(0.415)$ & 1.298 & $0.463^{* *}(0.203)$ & 1.589 & $0.07^{*}$ \\
\hline \multicolumn{6}{|l|}{ Family wealth } \\
\hline Income & $0.010(0.011)$ & 1.010 & $0.010^{*}(0.006)$ & 1.010 & $0.01^{* *}$ \\
\hline More than 1 house & $-0.001(0.063)$ & 0.999 & $-0.254^{* * *}(0.058)$ & 0.776 & $0.00^{* * *}$ \\
\hline Political identity $\square$ party member $=1 \square$ & $-0.132^{* *}(0.065)$ & 0.876 & $-0.065(0.067)$ & 0.937 & $0.00^{* * *}$ \\
\hline $\begin{array}{l}\text { Employment type Iwithin the public } \\
\text { economy }=1\end{array}$ & $-0.102(0.069)$ & 0.90 & $0.095(0.087)$ & 1.100 & 0.18 \\
\hline \multicolumn{6}{|l|}{ Class status (referent!lower) } \\
\hline Middle & $-0.606^{* * *}(0.117)$ & 0.545 & $-0.389^{* *}(0.156)$ & 0.678 & 0.46 \\
\hline Lower-middle & $\begin{array}{c}-0.362 * * * \\
(0.097)\end{array}$ & 0.696 & $-0.013(0.149)$ & 0.987 & 0.28 \\
\hline Upper-middle & $-0.903^{* * *}(0.331)$ & 0.405 & $-0.171(0.383)$ & 0.843 & 0.24 \\
\hline Upper & $0.225(1.290)$ & 1.252 & $0.290(0.798)$ & 1.337 & 0.42 \\
\hline
\end{tabular}

\section{Change in social status पreferent: going}

down!

Almost the same

$\begin{array}{lllll}-0.276^{* * *}(0.090) & 0.628 & -0.101(0.130) & 0.904 & 0.18\end{array}$

Going up

$-0.465^{* * *}(0.111) \quad 0.759 \quad-0.501^{* * *}(0.160) \quad 0.606$

$0.02^{* *}$

Cohort Ureferent: post-40s

\begin{tabular}{llllll} 
Post-50s & $-0.108^{*}(0.058)$ & 0.898 & $0.109^{*}(0.061)$ & 1.115 & 0.18 \\
\hline Post-60s & $-0.153^{* * *}(0.057)$ & 0.858 & $0.074(0.063)$ & 1.077 & 0.10 \\
\hline Post-70s & $-0.244^{* * *}(0.063)$ & 0.784 & $-0.078(0.071)$ & 0.925 & $0.04^{* *}$ \\
\hline Post-80s & $-0.260^{* * *}(0.084)$ & 0.771 & $-0.223^{* * *}(0.083)$ & 0.800 & 0.47 \\
\hline Post-90s & & & $-0.358^{* * *}(0.100)$ & 0.699 &
\end{tabular}

Usage of the internet [referent: never! 


\begin{tabular}{lcccccc} 
seldom & $-0.061^{* * *}(0.096)$ & 0.941 & $0.144^{*}(0.078)$ & 1.155 & $0.01^{* *}$ \\
\hline sometimes & $-0.158(0.125)$ & 0.854 & $0.065(0.082)$ & 1.067 & 0.1 \\
\hline regularly & $-0.193^{* *}(0.099)$ & 0.824 & $0.193^{* * *}(0.073)$ & 1.212 & $0.01^{* *}$ \\
\hline frequently & $-0.160(0.098)$ & 0.852 & $0.196^{* *}(0.076)$ & 1.217 & $0.01^{* *}$ \\
\hline
\end{tabular}

\section{Degree of marketization}

[referent: middle]

$\begin{array}{lccccc}\text { high } & -0.229^{* * *}(0.045) & 0.796 & -0.271^{* * *}(0.049) & 0.762 & 0.10 \\ \text { low } & -0.100(0.065) & 0.905 & -0.382^{* * *}(0.072) & 0.682 & 0.10\end{array}$

\section{Observations}

Log Likelihood
9,590

$-13,350.560$
10,086

$-12,447.510$

Note:

${ }^{*} \mathrm{p}<0.1 ;{ }^{* *} \mathrm{p}<0.05 ;{ }^{* * *} \mathrm{p}<0.01$

According to the modelling results, it can be seen that, consistent with previous empirical studies, rural residents have a higher perception of macrodistributive justice: the difference in the coefficient of the two years passed the test at $1 \%$ significance, showing that the difference between the perceptions of inequality of rural and urban residents decreased over the 10 years.

Although the public's perception of inequality was not necessarily strengthened because of the objective expansion of the disparity between rich and poor, in the past ten years, due to the development of modern factors such as population migration, national education and mass media, some obvious changes have taken place in the perception of justice.

\subsection{Results of the Analysis of the Explanatory Social Structure Variables}

First, the influence of economic income and family wealth on the perception of macrodistributive justice has increased, especially in the form of 'more than one house' as a measure of family wealth. In 2005 , the effect of income and housing was not noticeable; ten years later, respondents whose families owned more than one house were $22.4 \%$ less likely to perceive inequality than others. The ten years from 2005 to 2015 were the golden decade of China's real estate market, which created great wealth growth, and owners of more than one house were undoubtedly the direct beneficiaries of the rapid increase in housing prices. Based on structuralism's self-interest principle, people with a vested interest have a higher degree of perception of distribution justice, and hypothesis a2 passes the significance test. However, it is worth noting that while the influence on income became more significant in 2015, it was in the opposite direction to hypothesis a1, showing that an increase in income will, on the other hand, slightly increase the perception of distribution inequality. This article ascribes these results to the 
different growth speeds of income and housing prices. Studies have shown that China's national wealthto-income ratio has been rising since 1978 and that the sharp rise in asset prices, such as housing prices and stocks, has been an important factor in the rapid rise in the wealth-to-income ratio over the past decade (Piketty et al. 2019). In contrast, personal income grew much more slowly than housing prices, and despite the rise in income, rising house prices were more likely to create a sense of loss and deprivation, thereby reducing the public's perception of distributive justice.

Second, the influence of individual vertical relative deprivation on the perception of macrodistributive justice has increased. One of the important sources of individual relative deprivation is the vertical comparison of social status. Our analysis shows that the influence of subjective class status on the perception of distributive justice decreased over the ten years, but the influence of class change, especially 'going up', on the perception of macrodistributive justice significantly increased, as hypothesis a3 passed the significance test. To make a clearer comparison of the interaction between class status and class change, Figure 2 and Figure 3 are used to show the impact of changes in class on the sense of the equity of the macrodistribution in 2005 and 2015. Over the past decade, the evaluation of income distribution by the middle and above strata has further differentiated, especially among the upper-middle and upper stratum. If one's class goes down, one's perception of distributive justice will dramatically decrease, while going up in status will significantly increase one's acceptance of the distribution result. For the group whose class stayed almost the same, their perception of macrodistributive justice noticeably dropped after 10 years, showing their desire to go up in class and their dissatisfaction with the relative strata solidification. It can be seen that "local comparison" based on relative deprivation theory yields a better interpretation than "structural determinism" based on self-interest theory. During the upturn in the overall economy, people have high expectations for an upward change in their social status. Regarding vested interests, the higher one's stratum in society is, the higher one's expectations of social distribution advantages, and the experience of the relative deprivation of status and relative damage to benefits will strengthen one's perception of social macroinequality.

Third, the gap in the perception of macrodistributive justice between party members and nonparty members and between workers inside and outside the public economic system has narrowed. Ten years ago, consistent with our theoretical hypothesis, party members who lived with a less marketized economy were more likely to endorse the 'average principle', while after 10 years, the cognitive difference is no longer significant, and the difference of units inside and outside the public economic system no longer significantly influences the public's perception of justice. Hypothesis a4's passing the significance test shows that with the advancement of marketization reform, the principle of desert has gradually become a consensus.

\subsection{Results of the Analysis of the Explanatory Variables of Values}

First, the cohort differences in the perception of macrodistributive justice are significant, and the cognitive differentiation between different cohorts is becoming more noticeable. The 2005 model shows that the 
younger the cohort is, the higher the recognition of the principle of desert and the higher the perception of macrodistributive justice. Compared with the post-40s cohort, the cumulative probability of distribution inequality for the post-50s, post-60s, post-70s and post-80s cohorts decreased by $10.2 \%, 14.2 \%, 21.6 \%$ and $22.9 \%$, and hypothesis b1 passed the significance test. However, the attitude of people born between the 50s and 70s has changed in the past decade, and their perception of macrodistributive justice has shown a downward trend. Their attitude is diametrically opposed to that of the young cohorts, showing evident cohort differentiation.

Second, the critical role of education in the perception of distributive justice has been significantly enhanced. The data show that in 2005, under the controlled influence of income, social status and other factors, the effect of education level on the perception of distributive justice was not significant, while after 10 years, the more educated the respondents, the more critical they were of the macrodistribution results. Compared with the respondents with a primary school education, the cumulative probability of the choice of distribution inequality of respondents with high school, junior college, bachelor's and master's levels of education increased by $16.9 \%, 35.3 \%, 22.6 \%$ and $58.9 \%$, respectively, which supports the enlightenment role of education in the perception of inequality. First, the values of humanistic care and helping the weak and the poor conveyed by education make people agree more strongly with the ideal social form of equality and justice; second, education improves critical thinking skills, helping people to comprehensively and accurately recognize the disparity between rich and poor. The results of the analysis support hypothesis b2.

Third, internet media communication has strengthened people's perception and evaluation of social inequality. The results of the analysis show that in 2005, the internet influenced the perception of distributive justice to some extent, but in general, the use of the internet slightly increased people's tolerance for distribution differences; however, in 2015, the more frequently the internet was used, the more inclined the respondent was to recognize distribution inequality, and this opposite effect shows the complexity of the impact of internet media on the perception of justice. A study has shown that the usage of internet media breaks through the limitations of social communication structures, and under the influence of self-interested psychology, people have more opportunities to make downwards comparisons; therefore, to a certain extent, the internet may increase awareness of social equity (Zhu et al. 2018). However, with the advent of the internet economy, the influence of the relative deprivation mechanism of the internet may go in the opposite direction: the internet is gradually becoming the media of a desire production and consumption culture and is becoming a driving mechanism for upwards comparisons, which may cause a relative sense of disparity and deprivation, which will negatively affect the perception of social justice.

\subsection{Results of the Analysis of the Explanatory Institutional Change Variables}

The data analysis shows that, in terms of time, from 2005 to 2015, with the advancement of marketization reform, the public's acceptance of the macrodistribution results increased, supporting 
hypothesis $\mathrm{c} 1$. In regional terms, marketization reform expands the perception of social justice from the perspectives of both performance and values. With the deepening of the marketization transformation, the principle of desert will replace the average principle, and the higher the degree of regional marketization is, the more prominent the principle of desert is. Model 1 shows that in 2005, more marketized areas tended to recognize distributive justice, and until 2015 (shown in model 2), the trend remained constant. At the same time, in less marketized regions, while people are more inclined to agree on the average principle, the decade of economic development also brings a perception of macrodistributive justice. Model 2 shows that compared to areas with a moderate degree of marketization, the perception of distributive inequality in areas with a higher marketization degree decreased by $23.8 \%$, while it decreased by $31.8 \%$ in areas with a lower marketization degree, showing the nonlinear effects of the degree of marketization.

\section{Discussion}

This paper explains the mechanism of macrodistributive justice in the past ten years from the three perspectives of social structure, values and institutional changes. The data show that the objective income distribution gap is widening and the gap between rich and poor is becoming increasingly obvious; the public do have a somewhat negative attitude about some aspects of inequality, but in general, they do not think the current pattern of resource allocation is becoming increasingly unfair. The public's tolerance for income differentiation has increased to some extent, and this is helpful in interpreting the stability of the Chinese social structure at present. However, the perception of justice is uneven in regard to different groups. Traditional explanatory variables such as potential benefit differentiation and class change have brought about cognitive imbalance. At the same time, social factors such as housing, the internet, and education, which have developed and changed rapidly over the past decade, can lead to considerable differences in the perception of justice. The results of our analysis reveal the complexity and changeability of the perception of macrojustice: there is no simple correspondence between the objective benefit distribution and people's perception of justice, and the comparative perspective of the period under social change helps us to understand the cognitive mechanism of the perception of distributive justice in greater depth, which is of great significance for grasping the change in social attitudes in the transition period and evaluating the realistic influence of the differences in the objective distribution.

Consistent with previous studies, it was found that while objective economic status can influence attitudes towards inequality, groups with lower social status, such as farmers and groups from less marketized western regions, are not necessarily dissatisfied with the current level of inequality. At the same time, groups with higher economic status, faster growth in wealth, and an increase in social status tend to think the distribution is fair. However, it is noticeable that while the younger cohorts maintain an optimistic assessment of distributive justice, the older cohorts show concern about the distribution disparity, with significant intergenerational differentiation. Additionally, the enlightenment effect of education and the internet on the criticism of inequality is becoming increasingly evident. When groups from the middle class and upper class are disadvantaged in terms of class change, they show strong dissatisfaction with the resource distribution. 
There are two assumptions regarding the impact of socioeconomic change on attitudes towards inequality: adaptation theory and the resistance hypothesis (Aalberg 2003; Listhaug and Aalberg 1999). The former asserts that people will slowly adapt to the rise in inequality and accordingly adjust their tolerance for inequality, while the latter says that if economic and social changes are not consistent with people's values in the past, they will express strong dissatisfaction and resistance to income inequality. Policy judgements in the future on trends in inequality and their social effects should be based on solid and reliable research on public attitudes. In fact, in the process of marketization transformation with rapid economic growth, changes in the public's attitude are not binary, and reality may be more complex than theoretical assumptions. China's transformation practice shows that in the process of marketization reform, people's attitudes towards social inequality are not only adapting and accepting but also reviewing and critical. Deeper studies of people's awareness of income distribution in different groups and at different time stages can provide better interpretations of the social mechanism of stability and development in China, and these studies can also provide more useful guidelines for promoting social equity and justice.

\section{References}

Aalberg, T. (2003). Achieving justice: Comparative public opinions on income distribution (Vol. 7). Brill. Abercrombie, N., \& Turner, B. S. (1978). The dominant ideology thesis. British journal of sociology, 149170. https://doi.org/10/d9tkpr

Adams, J. S. (1965). Inequity In Social Exchange. In L. Berkowitz (Ed.), Advances in Experimental Social Psychology (Vol. 2, pp. 267-299). Academic Press. https://doi.org/10.1016/S0065-2601(08)60108-2

Burstein, P. (2003). The Impact of Public Opinion on Public Policy: A Review and an Agenda. Political Research Quarterly, 56(1), 29-40. https://doi.org/10/d28sh9

Deutsch, M. (1975). Equity, equality, and need: What determines which value will be used as the basis of distributive justice? Journal of Social issues. https://doi.org/10/dc8wmp

DiMaggio, P., Evans, J., \& Bryson, B. (1996). Have American's social attitudes become more polarized? American journal of Sociology, 102(3), 690-755. https://doi.org/10/dmjdgm

Efron, B., \& Tibshirani, R. J. (1994). An introduction to the bootstrap. CRC press.

Geschwender, J. A. (1967). Relative Deprivation and Social Justice: A Study of Attitudes to Social Inequality in Twentieth-Century England. By W. G. Runciman. Berkeley: University of California Press, 1966. 338 pp. Tables. \$6.50. Social Forces, 45(4), 596-597. https://doi.org/10/fk9xt9

Glenn, N. D., \& Simmons, J. L. (1967). Are regional cultural differences diminishing? Public Opinion Quarterly, 31(2), 176-193. https://doi.org/10/fq7hk7 
Hamilton, C. (2002). Overconsumption in Britain: A culture of middle-class complaint? Australia Institute.

Kluegel, J. R., \& Smith, E. R. (2017). Beliefs about inequality: Americans' views of what is and what ought to be. Routledge.

Li, J., \& Wu, X. (2012). Income Inequality and Fair Distribution: An Empirical Analysis of the Fair View of Chinese Urban Residents in the Transition Period. Chinese Social Sciences (China), 3(19), 1.

Li, L., \& Wang, P. (2018). Changes in Social Attitudes in Transitional China (2005-2015). Chinese Social Sciences (China), (3), 83-101.

Lipset, S. M., \& Ladd Jr, E. C. (1972). The politics of American sociologists. American Journal of Sociology, 78(1), 67-104. https://doi.org/10/d8w3fh

Listhaug, O., \& Aalberg, T. (1999). Comparative public opinion on distributive justice: A study of equality ideals and attitudes toward current policies. International Journal of Comparative Sociology, 40(1), 117. https://doi.org/10/frzzhg

Lu, C., \& Quan, X. (2015). The Impact of Media Use on Government Trust--An Empirical Study Based on CGSS2010 Data. International press (China), 37(5), 66-80.

McCarter, S. A. (2009). Legal and extralegal factors affecting minority overrepresentation in Virginia's juvenile justice system: A mixed-method study. Child and Adolescent Social Work Journal, 26(6), 533544. https://doi.org/10/cm4k7d

Menard, S. (2002). Applied logistic regression analysis (Vol. 106). Sage.

Ming, S. (2009). Market Transition and People's Perception of the Principles of Distributive Justice in Contemporary China. Sociological Studies, 3.

Phelan, J., Link, B. G., Stueve, A., \& Moore, R. E. (1995). Education, social liberalism, and economic conservatism: Attitudes toward homeless people. American Sociological Review, 126-140. https://doi.org/10/crvfmf

Piketty, T., Yang, L., \& Zucman, G. (2019). Capital accumulation, private property, and rising inequality in China, 1978-2015. American Economic Review, 109(7), 2469-96. https://doi.org/10/ggbwg3

Robinson, R. V., \& Bell, W. (1978). Equality, success, and social justice in England and the United States. American Sociological Review, 125-143. https://doi.org/10/dqrq9n

Saar, E. (2008). Different cohorts and evaluation of income differences in Estonia. International sociology, 23(3), 417-445. https://doi.org/10/fpc45t

Schor, J. B. (1998). The overspent American: Upscaling, downshifting, and the new consumer. Basic Books New York. 
Schor, J. B. (1999). The overspent American: Why we want what we don't need. HarperPerennial New York.

Schreiber, E. M. (1978). Education and change in American opinions on a woman for president. Public Opinion Quarterly, 42(2), 171-182. https://doi.org/10/b88v3k

Sun, L. (2011). The current rich and poor pattern in China. Unity (China), (2), 39-46.

Sun, M. (2009). Market Transformation and the People's View of Distribution Justice. Sociological Studies (China), (3), 78-88.

The growth of per capita disposable income of rural residents from 1978 to 2019. (n.d.). https://cyfd.cnki.com.cn/Article/N2020120302000244.htm. Accessed 22 August 2021

Verwiebe, R., \& Wegener, B. (2000). Social inequality and the perceived income justice gap. Social Justice Research, 13(2), 123-149. https://doi.org/10/fng3d9

Wegener, B. (2000). Political culture and post-communist transition-A social justice approach: Introduction. Springer.

Whyte, K. (2009). How do the Chinese people view the current social inequality. Sociological Studies (China), (1), 96-120.

Wu, X. (2009). Income inequality and distributive justice: A comparative analysis of mainland China and Hong Kong. The China Quarterly, 200, 1033-1052. https://doi.org/10/b2qg4p

Xie, Y. (2010). Understanding China's inequality. Society (China), 30(3), 1-20.

Zhang, H. (2004). Research on the Attitudes of Urban Residents to Social Inequality. Sociological Studies (China), (6).

Zhu, B., Miao, D., \& Li, L. (2018). Internet media and subjective fairness: paradoxes and explanations. Journal of Renmin University of China (China), 32(6), 78-89.

\section{Figures}




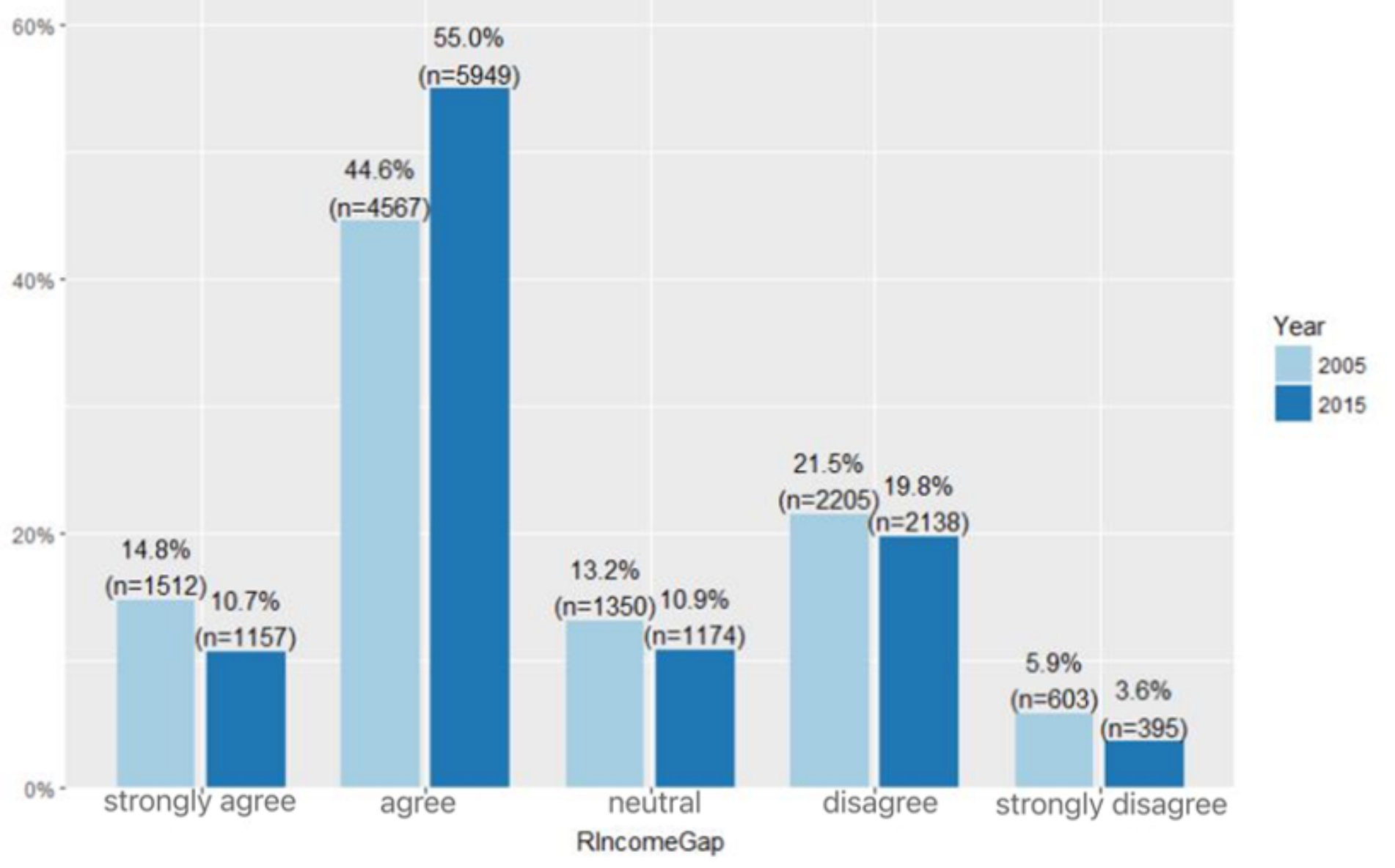

Figure 1

Distribution of the perception of distributive justice

2015

RIncomeGap

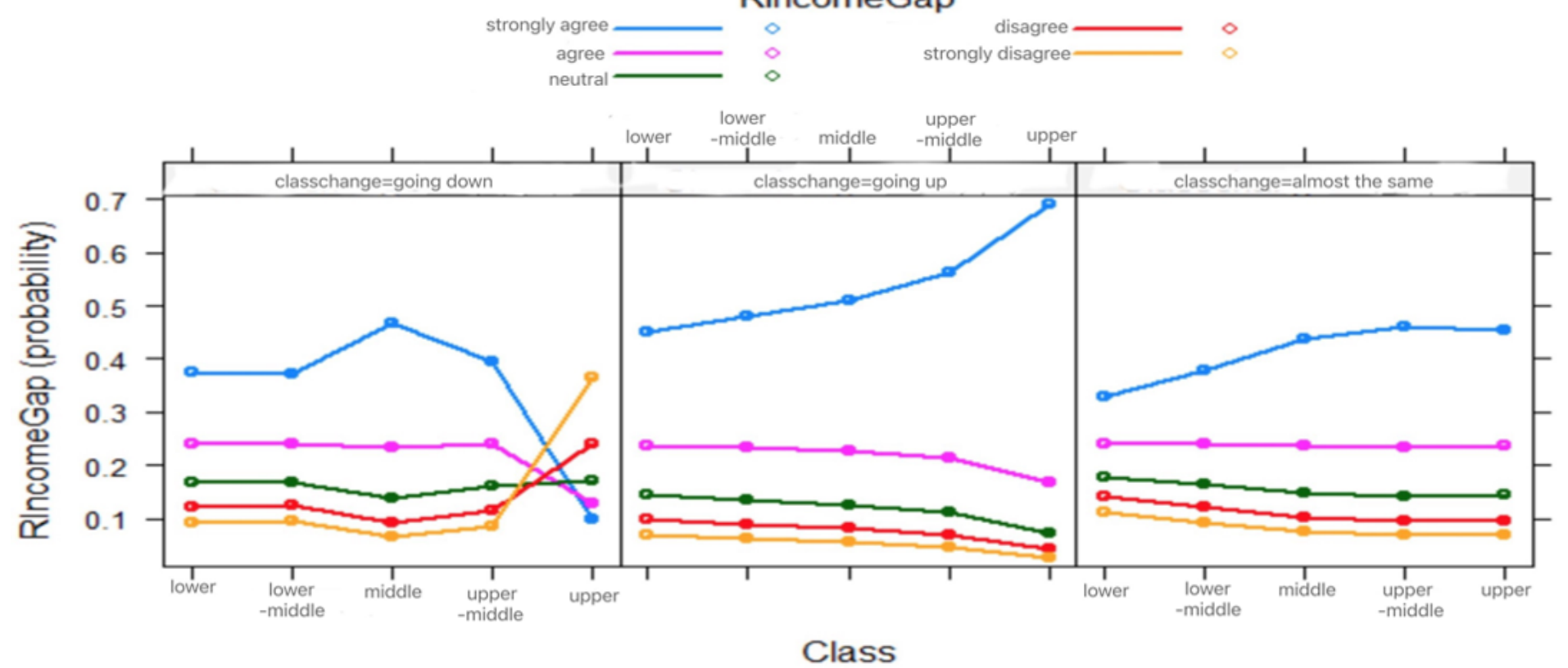


Figure 2

The influence of class change on the perception of macrodistributive justice (2015)

\section{5}

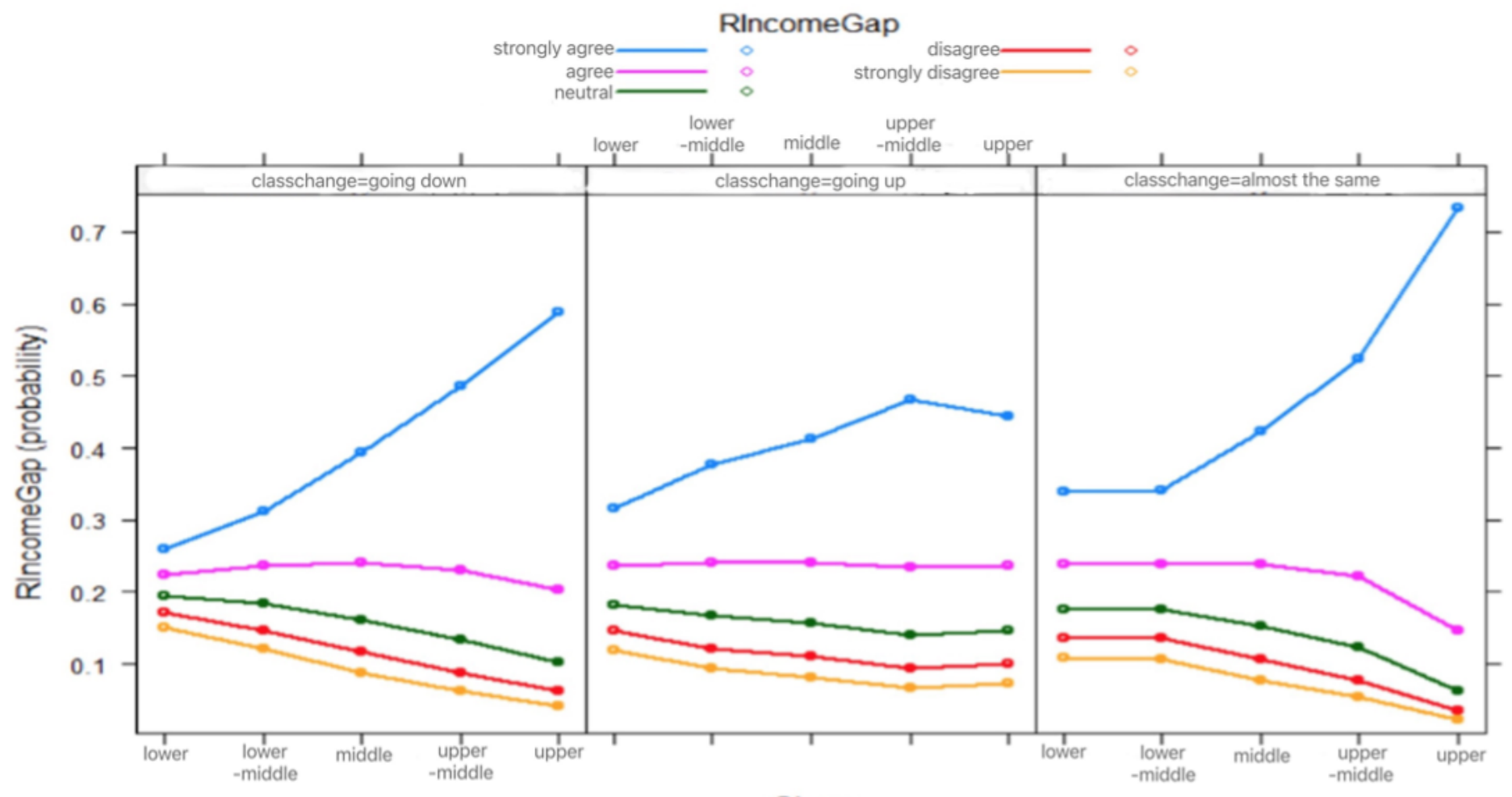

Class

\section{Figure 3}

The influence of class change on the perception of macrodistributive justice (2005) 